\title{
AVALIAÇÃO VISUAL E PESO CORPORAL DE BOVINOS DA RAÇA NELORE, EM VILHENA, RONDÔNIA
}

\author{
FARIAS, Rita de Cássia Caroline Oliveira ${ }^{1}$ \\ SILVA, Andrezza Miguel da ${ }^{2}$ \\ RIBEIRO, Fabricio Leonardo Alves ${ }^{2}$ \\ GUIRAUD, Ana Claudia Costa ${ }^{2}$
}

ISSUE DOI: $10.3738 / 21751463.3676$

\begin{abstract}
RESUMO: Objetivou-se verificar as características morfológicas por meio de escores de avaliação visual e sua associação com o peso corporal de bovinos machos da raça Nelore, em um rebanho elite, no município de Vilhena, Rondônia. A pesquisa foi realizada na Fazenda Martendal, localizada no Município de Vilhena - Rondônia, onde os animais foram criados a pasto e receberam suplementação proteica. Do rebanho foi selecionado um lote de 67 animais machos da raça Nelore, com idade entre 24 a 26 meses, todos Puros de Origem (PO) para avaliação do escore visual e do peso corporal. Analisando as notas referente à avaliação visual EPMU (estrutura, precocidade, musculosidade, umbigo), verificou-se valores de escore para estrutura de 3,85; precocidade de 3,79; musculosidade 3,58 e umbigo 3,31. Observou-se correlação alta e positiva entre peso corporal e estrutura $(0,70)$; peso corporal e precocidade $(0,64)$; peso corporal e musculosidade $(0,66)$. Assim, a avaliação visual mostra grande importância para a seleção em rebanhos da raça Nelore e a observação de correlação entre o peso do animal e caracteristicas morfológicas, mostra que é possível a seleção de determinada característica por meio da avaliação por escore visual, visando ganhos em desempenho produtivo.
\end{abstract}

Palavras-chave: Estrutura. Musculosidade. Pesagem. Precocidade.

\section{VISUAL EVALUATION AND BODY WEIGHT OF NELORE BREED CATTLE, IN VILHENA, RONDÔNIA}

SUMMARY: The objective of this study was to verify the morphological characteristics by means of visual evaluation scores and their association with the body weight of nelore breed cattle Nellore breed cattle in an elite herd in the municipality of Vilhena, Rondônia. The research was carried out at farm Martendal, located in the Municipality of Vilhena - Rondônia, where the animals were raised to pasture and received protein supplementation. From the herd, a batch of 67 male Nelore animals, aged 24 to 26 months, all of Pure of Origin (PO) were selected for evaluation of visual score and body weight. Analyzing the notes regarding the visual evaluation EPMU (structure, precocity, muscularity, umbilicus), score values were found for structure of 3,85; precocity of 3,79; muscularity 3,58 and umbilicus 3,31 . There was a high and positive correlation between body weight and structure $(0,70)$; body weight and precocity $(0,64)$; body weight and muscularity $(0,66)$. Thus, the visual evaluation shows great importance for selection in Nelore herds and the observation of correlation between animal weight and morphological characteristics, shows that it is possible to select a certain characteristic through visual score evaluation, objectifying for gains in productive performance.

Keywords: Structure. Muscularity. Weighing. Precocity.

\section{INTRODUÇÃO}

A bovinocultura de corte é um dos principais segmentos agropecuários brasileiros, com significativa participação no PIB do agronegócio do país. Nos últimos anos com o desenvolvimento

\footnotetext{
${ }^{1}$ Zootecnista

${ }^{2}$ Docente na Faculdade da Amazônia
} 
da cadeia pecuária, o Brasil passou a ocupar lugar de destaque no comércio mundial de carne, o que se deu em função do tamanho de rebanho, da produtividade animal e do volume de carne exportada (ABIEC, 2018).

De acordo com o CEPEA (2019) o PIB do agronegócio brasileiro apresentou estabilidade em 2018, com leve baixa de $0,01 \%$ no fechamento do ano. As exportações brasileiras de carne bovina alcançaram em 2018 o total de 1,64 milhões de toneladas, volume 11\% acima do registrado em 2017 e representou o maior volume já exportado pelo país. Ademais, esse recorde firma a posição do Brasil como principal exportador mundial do produto, porque trata-se do maior volume já exportado entre todos os países exportadores (ABIEC, 2019) e grande parte da carne produzida é oriunda de animais zebuínos especialmente os da raça Nelore (ABIEC, 2018).

A raça Nelore é umas das mais criadas no Brasil, ela apresenta adaptação ao ambiente tropical, rusticidade, resistência à parasitoses, alta prolificidade, qualidade de carcaça, entre outras características que levam a preferência por parte dos criadores. Com o desenvolvimento da pecuária de corte os produtores na tentativa de se manterem na atividade buscam cada vez mais a utilização de novas tecnologias que venham a promover ganhos em produtividade, destaque para o melhoramento genético do rebanho.

No Brasil no ano de 1968 teve início o melhoramento genético efetivo das raças zebuínas com a introdução da prova zootécnica do Controle de Desenvolvimento Ponderal pela Associação Brasileira dos Criadores de Zebuínos, em meados de 1980 foi marcado pelo lançamento do primeiro Sumário Nacional de Touros avaliado pela metodologia de modelos mistos, elaborado pela Associação Brasileira de Criadores de Zebu e Empresa Brasileira de Pesquisa Agropecuária (LOPEZ e REZENDE, 2001).

Uma das alternativas utilizadas para promover o melhoramento genético é a aquisição de animais geneticamente superiores, para serem usados na reprodução, na busca por aumentar a presença de genes responsáveis pela expressão de características de destaque econômico (ROSA et al., 2013).

Com o passar do tempo, diversas técnicas foram criadas e utilizadas em programas de melhoramento genético animal, onde a avaliação visual é um processo de seleção e vem sendo aplicada em várias circunstâncias: sistema de compra e descarte dos animais, distribuição de musculatura, precocidade na terminação, concepção de registros genealógicos, em julgamentos comparativos nas pistas de exposições agropecuárias e em acasalamentos dirigidos, em que muitos profissionais analisam o exterior dos animais em complemento a dados de genealogia, desempenho fenotípico e em avaliações genéticas, quando existentes (KOURY FILHO, 2005).

Para Faria et al. (2009) a seleção de animais por um biotipo adequado ao sistema produtivo é um aspecto determinante para aumentar a eficiência econômica da empresa rural e condição 
primordial para a sustentabilidade da atividade pecuária. Por meio dos escores de avaliação visual é possível reconhecer de forma prática e eficaz os indivíduos superiores para estrutura corporal, precocidade, musculosidade e umbigo.

Nesse sentido, objetivou-se verificar as características morfológicas por meio de escores de avaliação visual e sua associação com o peso corporal de bovinos machos da raça Nelore, em um rebanho de elite, no município de Vilhena, Rondônia.

\section{MATERIAL E MÉTODO}

A pesquisa foi realizada no ano de 2018 na Fazenda Martendal que possui uma área de 1000 alqueires, localizada no Município de Vilhena - Rondônia. Na propriedade os animais são criados em sistema de produção a pasto, formado pela espécie Brachiaria brizantha e recebem ainda suplementação proteinada (150 g/animal/dia).

Foi selecionado um lote de 67 animais machos da raça Nelore, com idade entre 24 a 26 meses, todos Puros de Origem (PO) para avaliação do escore visual e do peso corporal. A seleção deste grupo deu-se pelo fato de que todos os animais faziam parte do mesmo grupo de contemporâneos, uma vez que eram oriundo da mesma fazenda, nascidos no mesmo ano e manejados de maneira similar à desmama e ao sobreano.

No dia de avaliação, realizou-se a pesagem dos animais em balança eletrônica digital e em seguida estes foram soltos, passando de três em três em uma área do curral aberta para serem avaliados pelo sistema de EPMU (KOURY FILHO, 2005). A avaliação visual foi realizada por três avaliadores treinados.

Os escores visuais e o peso corporal dos bovinos machos da raça Nelore foram analisados por estatística descritiva por meio do programa estatístico SISVAR (FERREIRA, 2008). Além disso, procedeu-se a análise de correlação entre o escore visual e o peso corporal realizada com o auxílio do programa Excel (MICROSOFT OFFICE, 2010).

\section{RESULTADO E DISCUSSÃO}

As características morfológicas verificadas por meio de escores de avaliação visual e o peso corporal de bovinos machos da raça Nelore, podem ser visualizados na Tabela 1. Os animais apresentaram valor médio de peso de $385 \mathrm{~kg}$; estrutura 3,85; precocidade 3,79; musculosidade 3,58 e umbigo 3,31 .

O peso corporal médio dos bovinos de $385 \mathrm{~kg}$ foi semelhante ao verificado em outros estudos realizados com a mesma raça, idade e em sistema de produção a pasto (ASSUMPÇÃO $e t$ al., 2013; BRAGA LÔBO et al., 2002; MARQUES et al., 2012; KAROLEWSKI et al., 2018). O 
monitoramento do peso corporal dos animais é de grande importância para inferir sobre os aspectos de eficiência do sistema de produção. Descrições de mudanças de peso vivo com a idade são necessárias para a tomada de decisão no planejamento, seleção e cruzamento, uma vez que o ganho de peso vivo afeta os custos de produção (MADALENA et al., 2003).

Os bovinos apresentaram estrutura de 3,85 (escore médio), valor que encontra-se entre o descrito para animais adultos, que varia basicamente entre 3 a 6 (KOURY FILHO et al., 2015). Ainda, segundo esses autores, nenhum dos extremos é desejado para uma pecuária de corte eficiente. Animais muito pequenos, apesar da baixa necessidade de mantença, produzem progênies com pequeno potencial de crescimento, enquanto que animais muito grandes, apesar do elevado potencial de crescimento transmitido à progênie têm sua produtividade reduzida devido à elevada necessidade de mantença (MOTA et al., 2014).

A precocidade observada de 3,79 diz respeito a um animal tendendo a tardio, já com a relação de 40 a 45\% de costelas com relação a sua altura (KOURY FILHO et al., 2015), além disso, apresenta menor velocidade de deposição de gordura na carcaça, afetando negativamente a qualidade da carne produzida.

O escore de estrutura e precocidade (médio) apresentado pelos bovinos está relacionado à animais que apresentam menor área para deposição de carne e de gordura de acabamento mais precoce, por apresentarem essas características mais baixas para ambos (LIMA, 2011). Os animais quando apresentam escore de estrutura mais próximo de 6, é indicativo de maior comprimento corporal e de profundidade de costelas (JOSAHKIAN; LUCAS; MACHADO, 2009).

Os bovinos apresentaram uma média de escore de 3,58 para a musculosidade, estando relacionado a animais sem muita expressão de massas musculares, e no que diz respeito a essa característica, altos escores são desejados para se obter melhores resultados em rendimentos de carcaça (KOURY FILHO et al., 2015).

Para a característica umbigo verificou-se uma média de 3,31; valor de escore desejado, por não ser tão reduzido e nem tão pendulosos, caracteristica que poderia comprometer a funcionalidade do animal a campo (KOURY FILHO et al., 2015). 
Tabela 1. Estatística descritiva das características peso corporal $(\mathrm{kg})$ e EPMU de machos da raça Nelore, em um rebanho elite, no município de Vilhena, Rondônia.

\begin{tabular}{lccccccc}
\hline \multicolumn{1}{c}{ Característica } & N & Média & Mínimo & Máximo & EPM & DP & CV\% \\
\hline Peso corporal $(\mathrm{kg})$ & 67 & 385 & 316 & 481 & 3,23 & 26,44 & 6,91 \\
E & 67 & 3,85 & 2 & 6 & 0,14 & 1,15 & 30,07 \\
P & 67 & 3,79 & 2 & 6 & 0,11 & 0,94 & 24,96 \\
M & 67 & 3,58 & 2 & 6 & 0,14 & 1,15 & 32,29 \\
U & 67 & 3,31 & 2 & 5 & 0,09 & 0,80 & 24,19
\end{tabular}

Número de observações (N), média (Média), valor mínimo (Min), valor máximo (Max), erro padrão da média (EPM), desvio-padrão (DP), coeficiente de variação $(\mathrm{CV})$, para as características estrutura $(\mathrm{E})$, precocidade $(\mathrm{P})$, musculatura (M) e umbigo (U).

Fonte: Dados da pesquisa.

O valor médio de EPMU verificado nos animais encontra-se dentro do intervalo de escore de 2 a 4 estabelecido pela Associação Brasileira dos Criadores de Zebu (ABCZ) e considerado ideal para os padrões da raça Nelore, conceitualmente escores intermediários (JOSAHKIAN et al., 2003).

Quando analisou-se a distribuição dos escores de EPMU (Tabela 2), observou-se maiores frequências para os escores 3 e 4, que conceitualmente são escores atribuídos às características de E, P e M intermediário; e de umbigo,que está entre o de pequena dimensão e o de maior dimensão (FOGAGNOLI et al., 2010). Segundo Josahkian, Machado e Koury Filho (2003) o umbigo ideal, é aquele que está entre o escore 3 e 4, como observado pela maioria dos animais.

A distribuição dos animais em cabeceira, meio e fundo de lote (Tabela 3), mostrou que menores valores percentuais são encontrados no fundo para estrutura (14,87\%), precocidade $(6,75 \%)$ e musculosidade (18,92\%). Enfatizando, que por melhor que seja o grupo de contemporâneos, este possui animais que, comparativamente, devem ser classificados em fundo, e por pior que seja um grupo de contemporâneos, se deve apartar a cabeceira, ou seja, todo grupo de contemporâneos pode e deve ser conceitualmente separado em cabeceira, meio e fundo (KOURY FILHO, 2005).

Tabela 2. Distribuição (\%) por escores para as características EPMU de machos da raça Nelore, em um rebanho elite, no município de Vilhena, Rondônia. 


\begin{tabular}{lcccccc}
\hline & \multicolumn{7}{c}{ Escore } \\
\cline { 2 - 7 } Características & $\mathbf{1}$ & $\mathbf{2}$ & $\mathbf{3}$ & $\mathbf{4}$ & $\mathbf{5}$ & $\mathbf{6}$ \\
\hline E & 0 & 14,87 & 21,62 & 36,49 & 17,57 & 9,45 \\
$\mathrm{P}$ & 0 & 6,75 & 33,79 & 39,19 & 16,22 & 4,05 \\
$\mathrm{M}$ & 0 & 18,92 & 32,43 & 27,03 & 14,87 & 6,75 \\
$\mathrm{U}$ & 0 & 17,56 & 41,90 & 36,49 & 4,05 & 0 \\
\hline
\end{tabular}

Características de estrutura (E), precocidade (P), musculatura (M) e umbigo (U).

Fonte: Dados da pesquisa.

Avaliando a relação entre peso corporal e as características morfológicas (Tabela 4) observou-se a existência de correlação positiva e alta $(\mathrm{P}>0,01)$ entre peso corporal e estrutura $(0,70)$; peso corporal e precocidade $(0,64)$; peso corporal e musculosidade $(0,66)$. Essa relação ocorre pois os aspectos de estrutura, precocidade e musculosidades são componentes avaliados no corpo do animal. Dessa forma, existe a possibilidade de se ter animais com maior peso corporal e consequentemente maior estrutura, precocidade e musculosidade.

Tabela 3. Percentuais de cabeceira, meio e fundo referente às características $\mathrm{E}, \mathrm{P}$ e $\mathrm{M}$ de machos da raça Nelore, em um rebanho elite, no município de Vilhena, Rondônia.

\begin{tabular}{cccc}
\hline Característica & Cabeceira (\%) & Meio (\%) & Fundo (\%) \\
\hline E & $27,05 \%$ & $58,11 \%$ & $14,87 \%$ \\
P & $20,27 \%$ & $72,98 \%$ & $6,75 \%$ \\
M & $21,62 \%$ & $59,46 \%$ & $18,92 \%$ \\
\hline
\end{tabular}

Características de estrutura (E), precocidade (P), musculatura (M) e umbigo (U).

Fonte: Dados da pesquisa.

O estudo da curva de crescimento de bovinos de corte com base no peso corporal e medidas nas fases iniciais do desenvolvimento animal são características importantes na determinação a eficiência econômica e são utilizados na avaliação genética de programas de melhoramento (FONSECA et al., 2016). Além do estudo do peso corporal, as características de estrutura, precocidade e musculosidade do animal, podem ser utilizadas para compor o programa de seleção do rebanho, na busca por melhorias no desempenho produtivo dos animais.

Tabela 4. Correlação entre o peso corporal e escore visual (estrutura, precocidade e musculosidade) de machos da raça Nelore, em um rebanho elite, no município de Vilhena, Rondônia. 


\begin{tabular}{ccccc}
\hline $\begin{array}{c}\text { Peso } \\
\text { Perporal }\end{array}$ & E & P & M & U \\
$\begin{array}{c}\text { corporal } \\
\text { E }\end{array}$ & $0,70(* *)$ & & & \\
P & $0,64(* *)$ & $0,34\left(^{*}\right)$ & & \\
M & $0,66(* *)$ & $0,35\left(^{*}\right)$ & $0,80(* *)$ & \\
$\mathrm{U}$ & $-0,04$ & $-0,11$ & 0,11 & 0,13 \\
\hline
\end{tabular}

(**) Efeito da correlação significativo ao nível de $1 \%$ e $\left(^{*}\right)$ de $5 \%$ de probabilidade, respectivamente. Fonte: Dados da pesquisa.

\section{CONCLUSÃO}

A avaliação visual tem grande importância para a seleção em rebanhos da raça Nelore, permitindo a busca por equilíbrio em termos de estrutura, precocidade, musculosidade e umbigo.

A ocorrência de correlação entre o peso do animal e caracteristicas morfológicas (estrutura, precocidade e musculosidade), mostra que é possível a seleção de determinada característica por meio da avaliação por escore visual, visando ganhos em desempenho animal.

\section{REFERÊNCIAS}

ABIEC - Associação Brasileira das Indústrias Exportadoras de Carnes. 2019. Exportações brasileiras de carne bovina fecham 2018 com recorde histórico. Disponível em: $\langle$ http://www.abiec.com.br/download/exportacoes\%20fecham\%20com\%20recorde.pdf $>$. Acesso em: 09 jun. 2019.

ABIEC - Associação Brasileira das Indústrias Exportadoras de Carnes . 2018. Rebanho bovino Brasileiro. Disponível em: <http://www.abiec.com.br/3rebanho.asp>. Acesso em: 20 julho 2018.

ASSUMPÇÃO, T.I.et al. Características reprodutivas de machos bovinos da raça Nelore da fase pré-púbere à maturidade sexual. Revista Brasileira de Ciência Veterinária, v.20, n.3, p.148-154, 2013.

BRAGA LÔBO, R.N.et al. Correlações entre características de crescimento, abate e medidas corporais em tourinhos da raça Nelore. Revista Ciência Agronômica, v.33, n.2, p.5-12, 2002. Centro de Estudos Avançados em Economia Aplicada(CEPEA). 2019. PIB-agro/cepea: PIB do agronegócio fecha 2018 com estabilidade. Disponível em:< https://www.cepea.esalq.usp.br/br/releases/pib-agro-cepea-pib-do-agronegocio-fecha-2018-comestabilidade.aspx >. Acesso em: 09 jun. 2019.

FARIA, C.U.et al.Avaliação genética de características de escores visuais de bovinos da raça Nelore da desmama até a maturidade.Revista Brasileira de Zootecnia, v.38, n.7, p.11911200,2009 . 
FERREIRA, D.F. SISVAR: um programa para análises e ensino de estatística.Revista Cientifíca Symposium, v.6, n.2, p.36-41, 2008.

FOGAGNOLI, A.F.M.et al.. Morfometria, avaliações visuais (EPMURAS) e desempenho em animais da raça nelore. Caderno de Pós-Graduação, v.1, n.1, p.1-9, 2010.

JOSAHKIAN, L.A.; MACHADO, C.H.C.; KOURY FILHO, W. Programa de melhoramento genético das raças zebuínas - Manual de Operação. Uberaba: ABCZ, 2003. 98 p.

JOSAHKIAN, L.A.; LUCAS, C.H.; MACHADO, C.H.C. Manual do serviço de registro genealógico das raças zebuínas e PMGZ. Uberaba: ABCZ, 2009. 190 p.

KAROLEWSK, L.S.L.et al. Desempenho ponderal de touros nelore inteiros, imunocastrados e orquiectomizados. Enciclopédia Biosfera, v.15 n.28, p.390-397, 2018.

KOURY FILHO, W. Escores visuais e suas relações com características de crescimento em bovinos de corte. Jaboticabal: Universidade Estadual Paulista, 2005. 80p. Tese (Doutorado em Zootecnia - Produção Animal). Faculdade de Ciências Agrárias e Veterinárias, 2005.

KOURY FILHO, W.et al. Estimativas de herdabilidade e correlações para escores visuais, peso e altura ao sobre ano em rebanhos da raça Nelore. Revista Brasileira de Zootecnia, v.38, n.12, p.2362-2367, 2009.

KOURY FILHO, W.et al. Avaliação visual - EPMURAS descritivo. Caderno de Ciências Agrárias. Suplemento 1. v.7, n.1, 2015.

LIMA, M.R.P. Parâmetros genéticos para características produtivas, reprodutivas e escores visuais em bovinos da raça Nelore. 2011. 71 f. Dissertação (Mestrado em Ciências Animais)Universidade de Brasília, Brasília, 2011.

FONSECA, W.J.L.et al. application of random regression models for growth traits of nellore cattle in brazil. Nucleus Animalium, v.8, n.2, p-45-54, 2016. ISSN 2175-1463. Disponível em: <http://nucleus.feituverava.com.br/index.php/animalium/article/view/1657/2148 >. Acesso em: 2019. doi:http://dx.doi.org/10.3738/1982.2278.1657.

LOPES, M.A.B.; REZENDE, E.M.M. ABCZ: Histórias e Histórias. São Paulo: Com desenho Estúdio e Editora. 2ed. 2001, 381 p.

MADALENA, F.E.; TEODORO, R.L.; MADUREIRA, A.P. Relationships of weight and height with age in hybrid Holstein-Friesan/Guzera females. Genetics and Molecular Research, v.2, n.3, p.271-278, 2003.

MARQUES, E.G.; MAGNABOSCO, C.U.; LOPES, F.B. Índices de seleção para bovinos da raça Nelore participantes de provas de ganho em peso em confinamento. Revista Brasileira de Saúde e Produção Animal, v.13, n.3, p.669-681, 2012.

MICROSOFT OFFICE. MicrosoftExcel. 2010.

MOTA, L.F.M.et al. Estrutura corporal (Frame Size) e influencias no desempenho produtivo de bovinos de corte. Boletim técnico, v.2, n.1, 2014. 
ROSA, A.N.; MENEZES, G.R.O.; EGITO, A.A. Recursos genéticos e estratégias de melhoramento. In: ROSA, A.N.et al. Melhoramento genético aplicado em gado de corte: Programa GeneplusEmbrapa/ Brasília: Embrapa, 2013. p.11. 